\title{
Neuroinvasive West Nile Virus Disease in Canada. The Saskatchewan Experience
}

\author{
José F. Téllez-Zenteno, Gary Hunter, Lizbeth Hernández-Ronquillo, \\ Edrish Haghir
}

\begin{abstract}
Background: West Nile virus (WNV) is a virus of the family Flaviviridae. The main route of human infection is through the bite of an infected mosquito. Approximately $90 \%$ of WNV infections in humans are asymptomatic, but neurologic manifestations can be severe. Methods: This study reviews the clinical profile of cases with neuroinvasive West Nile infection (NWNI) reported by the Surveillance program of the government of Saskatchewan in the Saskatoon Health Region (SHR). In 2007, 1456 cases of human West Nile cases were reported by the government of Saskatchewan in the whole province. One hundred and thirteen cases had severe symptoms of NWNI (8\%), 1172 (80\%) cases had mild symptoms of WNI and $171(12 \%)$ had asymptomatic disease. Three hundred and fifty six cases were reported in the SHR, where 57 (16\%) fulfilled criteria for NWNI. Results: From the 57 cases, 39 (68\%) were females. Nine (16\%) patients had a history of recent camping, two (4\%) reported outdoor sports and four (8\%) reported outdoor activities not otherwise specified. Twenty five patients had headache (43.9\%), 25 confusion (42.1\%), 23 meningitis (40.4\%), 17 encephalitis (29.8\%), 14 encephalopathy (24.6\%), 11 meningoencephalitis $(19.3 \%)$, 10 tremor $(17.5 \%)$, acute flaccid paralysis 10 $(17.5 \%)$, myoclonus $1(1.8 \%)$, nystagmus $2(3.5 \%)$, diplopia $2(3.5 \%)$, dizziness $2(3.5 \%)$. Three patients died related with comorbidities during admission. Conclusion: During a year of high occurrence of WNI in Saskatchewan, 16\% of cases developed NWNI. The recognition of neurological complications associated with WNI is important to improve their referral to tertiary centers.
\end{abstract}

RÉSUMÉ: Maladie neuroinvasive due au virus du Nil occidental au Canada. L'expérience de la Saskatchewan. Contexte : Le virus du Nil occidental (VNO) est un virus de la famille des Flaviviridae. La principale voie d'infection chez l'humain est la piqûre d'un moustique infecté. À peu près $90 \%$ des infections par le VNO chez l'humain sont asymptomatiques. Cependant les manifestations neurologiques peuvent être sévères. Méthode : Cette étude revoie le profil clinique des cas atteints de neuroinfection par le VNO (NVNO) rapportés par le programme de surveillance du gouvernement de la Saskatchewan dans la région sanitaire de Saskatoon. En 2007, 1456 cas d'infection par le VNO dans toute la province ont été rapportés par le gouvernement de la Saskatchewan. Cent treize cas présentaient des symptômes sévères de NVNO (8\%), 1 172 (80\%) cas présentaient des symptômes légers de NVNO et 171 cas (12\%) étaient asymptomatiques. Trois cent cinquante-six cas ont été rapportés dans la région sanitaire de Saskatoon et $57(16 \%)$ respectaient les critères de NVNO. Résultats : Parmi ces 57 cas, 39 (68\%) étaient des femmes. Neuf patients (16\%) rapportaient être allés camper récemment, 2 patients (4\%) rapportaient avoir fait des sports à l'extérieur et 4 patients $(8 \%)$ rapportaient avoir fait des activités non spécifiées à l'extérieur. Vingt-cinq patients présentaient une céphalée (43\%), 25 présentaient de la confusion $(42,1 \%), 23$ présentaient une méningite (40,4\%), 17 (29,8\%) présentaient une encéphalite, 14 (24,6\%) présentaient une encéphalopathie, 11 (19,3\%) présentaient une méningoencéphalite, 10 $(17,5 \%)$ présentaient du tremblement, $10(17,5 \%)$ présentaient une paralysie flasque, $1(1,8 \%)$ présentait de la myoclonie, 2 (3,5\%) présentaient un nystagmus, $2(3,5 \%)$ présentaient de la diplopie et $2(3,5 \%)$ présentaient des étourdissements. Trois patients sont décédés de comorbidités pendant l'hospitalisation. Conclusion : Au cours d'une année où la fréquence des infections par le VNO était élevée en Saskatchewan, 16\% des cas ont présenté une NVNO. La détection des complications neurologiques associées à l'infection par le VNO est importante pour améliorer l'accès de ces patients à des centres de soins tertiaires.

Can J Neurol Sci. 2013; 40: 580-584

West Nile virus (WNV) is a virus of the family Flaviviridae. It is found in both tropical and temperate regions. It mainly infects birds, but is known to infect humans, horses, dogs, cats, bats, chipmunks, skunks, squirrels, domestic rabbits, crows, robins, crocodiles and alligators ${ }^{1}$. The main route of human infection is through the bite of an infected mosquito. Approximately $90 \%$ of West Nile Virus infections (WNVI) in humans are without any symptoms ${ }^{2}$. West Nile virus has been described in Africa, Europe, the Middle East, west and central Asia, Oceania, and most recently, North America ${ }^{1}$.

In Canada, the first positive bird was detected in Ontario in 2001. West Nile virus was first reported in humans in Canada in 2002 in Ontario and Quebec ${ }^{3}$. The number of cases of WNVI in Canada has fluctuated over the years. The number of cases according to the Public Health Agency of Canada (PHAC) from 2002 is displayed in Figure 1. Cases have now been reported in all the Canadian provinces with the highest number of cases in 2003 (414 cases), 2004 (1481 cases) and 2007 (2215 cases) ${ }^{3}$. Since 2008 the rates have been low, probably as a result of prevention measures implemented by the government of Canada.

From the Division of Neurology, Department of Medicine, University of Saskatchewan, Saskatoon, Saskatchewan, Canada.

Received November 12, 2012. Final Revisions Submitted January 21, 2013. Correspondence to: José F. Téllez-Zenteno, Department of Medicine, Division of Neurology, Royal University Hospital, Saskatoon, Saskatchewan, S7N 0W8, Canada. Email: jftellez@yahoo.com 


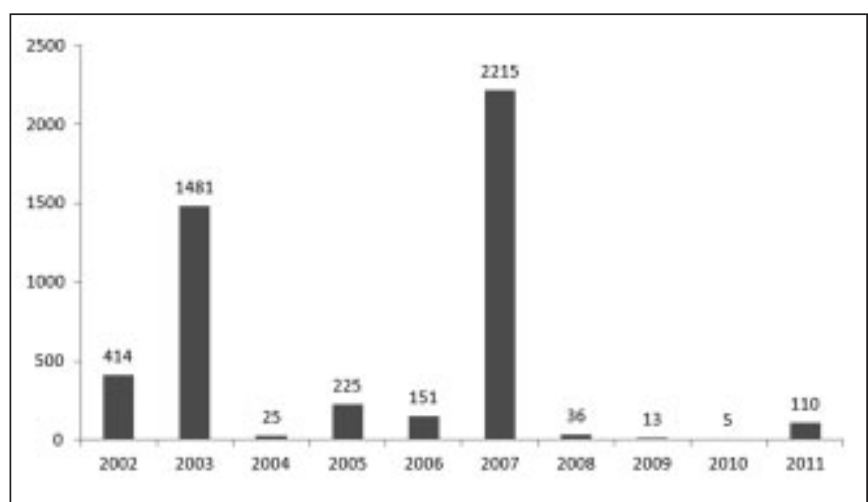

Figure 1: This figure shows the cases of WNI reported in Canada since 2002. The largest outbreak reported in Canada was in 2007, which is the year of our study.

The year 2007 saw record numbers of WNVI in Canada. The PHAC reported one case in Nova Scotia, two in Quebec, 12 in Ontario, 578 in Manitoba, 1285 in Saskatchewan, 318 in Alberta and 19 in $\mathrm{BC}^{3}$. This study focuses on the clinical description of the neuroinvasive West Nile infection (NWNI) of West Nile infection reported in 2007 in the Saskatoon Health Region (SHR).

\section{Methods}

\section{Objective: To review the large outbreak of West Nile infection} in Canada, focusing on the cases of NWNI in the SHR

Source of information: West Nile Virus national surveillance is a collaborative effort between the PHAC, provincial and territorial Ministries of Health, the Canadian Cooperative Wildlife Health Centre, Health Canada's First Nations and Inuit Health Branch, Canadian Blood Services, and Héma-Québec ${ }^{3}$. Since 2003 the government of Canada and provincial health regions have reported and collected epidemiological data about the number of cases per year, in order to identify risk factors and promote prevention. The province of Saskatchewan experienced its first ever outbreak of WNV during the summer of 2003, recording 937 clinically confirmed cases of WNV. Eight hundred and fifty eight $(91 \%)$ cases manifested as West Nile Fever (WNF), 63 (7\%) as NWNI, $10(1 \%)$ were asymptomatic, and 16 (1\%) cases were categorized with unknown manifestation. For this report we used the information reported by the government of Saskatchewan and the government of Canada using the West Nile Virus national surveillance.

Case diagnostic test criteria: We used the standard criteria composed by the PHAC, which is the detection of flavivirus antibodies in a single serum or cerebrospinal fluid (CSF) sample using a WNV IgM ELISA without confirmatory neutralization serology (e.g. Plaque Reduction Neutralization Test -PRNT) ${ }^{3}$.

Case definition for NWNI. For the purpose of this study, the Saskatoon Health Region (SHR) provided the researchers with a list of 71 cases with potential WNI who were admitted one of three Saskatoon hospitals in 2007. Not all patients that were admitted to the hospital necessarily had NWNI. Some of them were admitted because of other medical reason but had positive serology. This initial list allowed us to identify all the potential cases with NWNI. The cases were reviewed by a neurology resident who was specifically trained to perform data extraction. Cases were discussed with two neurologists and a final classification was performed. To define a case of NWNI, we use the definition of the PHAC ${ }^{3}$. The definition for NWNI in our series was as follows: a) History of exposure in an area where WNV activity is occurring b) or history of exposure to an alternative mode of transmission and c) onset of fever. In addition to this criteria a recent onset of at least one of the following: 1) encephalitis (acute signs of central or peripheral neurological dysfunction), 2) or viral meningitis (pleocytosis and signs of infection e.g., headache, nuchal rigidity), 3) or acute flaccid paralysis (e.g., poliomyelitis-like syndrome or GuillainBarre-like syndrome), 4) Movement disorders (e.g., tremor, myoclonus), 5) or Parkinsonism or Parkinsonian-like conditions (e.g., cogwheel rigidity, bradykinesia, postural instability). Other emerging clinical syndromes were considered such as: myelopathy, rhabdomyolysis, peripheral neuropathy; polyradiculoneuropathy; optic neuritis; and acute demyelinating encephalomyelitis (ADEM). All the charts were reviewed in order to apply the definition. Fifty-seven (80\%) cases met criteria for NWNI and the rest were classified as West Nile fever.

\section{RESULTS}

Outbreak in Saskatchewan: In 2007, 1456 cases of human West Nile cases were reported by the government of Saskatchewan as a result of the surveillance program. One hundred and thirteen (8\%) cases had NWNI, 1172 (80\%) cases had mild symptoms of WNI, 171 (12\%) had asymptomatic disease (See Figure 2A).

Outbreak in the SHR: 2007 was a record year for WNVI in the SHR, with four times the number of human cases reported compared to 2003. A total of 356 cases of WNVI were reported in 2007, including 36 cases with NWNI (10\%), 304 (85\%) with an isolated febrile syndrome, and $16(5 \%)$ asymptomatic with positive serology (Figure 2B). The rate for 2007 was 122.63 per 100,000 population compared to 21.9 in 2003. In total, $69 \%$ of cases $(245 / 356)$ were from Saskatoon. While information on travel is not available for all cases, a significant proportion of urban cases did not travel outside the city in the relevant period. The estimated rate for Saskatoon was 117.94 per 100,000 population compared to the average rural rate of 144.59 per 100,000 . Fifty-nine percent of the 2007 cases were male (209/356). The age of cases ranged from 6 to 90 years, with the median age 49 years. Seventy percent of cases (252/357) were 40 years of age or older. West Nile virus was a contributing factor to one death in an individual with underlying health conditions.

Cases with NWNI: 57 cases met criteria for NWNI. Thirty nine $(68 \%)$ were females. Nine $(16 \%)$ patients were camping, two $(4 \%)$ reported outdoor sports and four (8\%) reported outdoor activities. The rest of patients did not perform any outside activity. Nine (16\%) patients had diabetes, 11(19\%) renal failure, 4 (7\%) chronic obstructive pulmonary disease (COPD) 2 (4\%), hypertension, and 2 (4\%) had some form of immunosuppression. Sixteen patients $(28 \%)$ were smokers and $7(12 \%)$ were alcoholics. Overall the rate of NWNI using the review of the charts and applying criteria was $16 \%$, compared with the $10 \%$ reported by the government of Saskatchewan. 


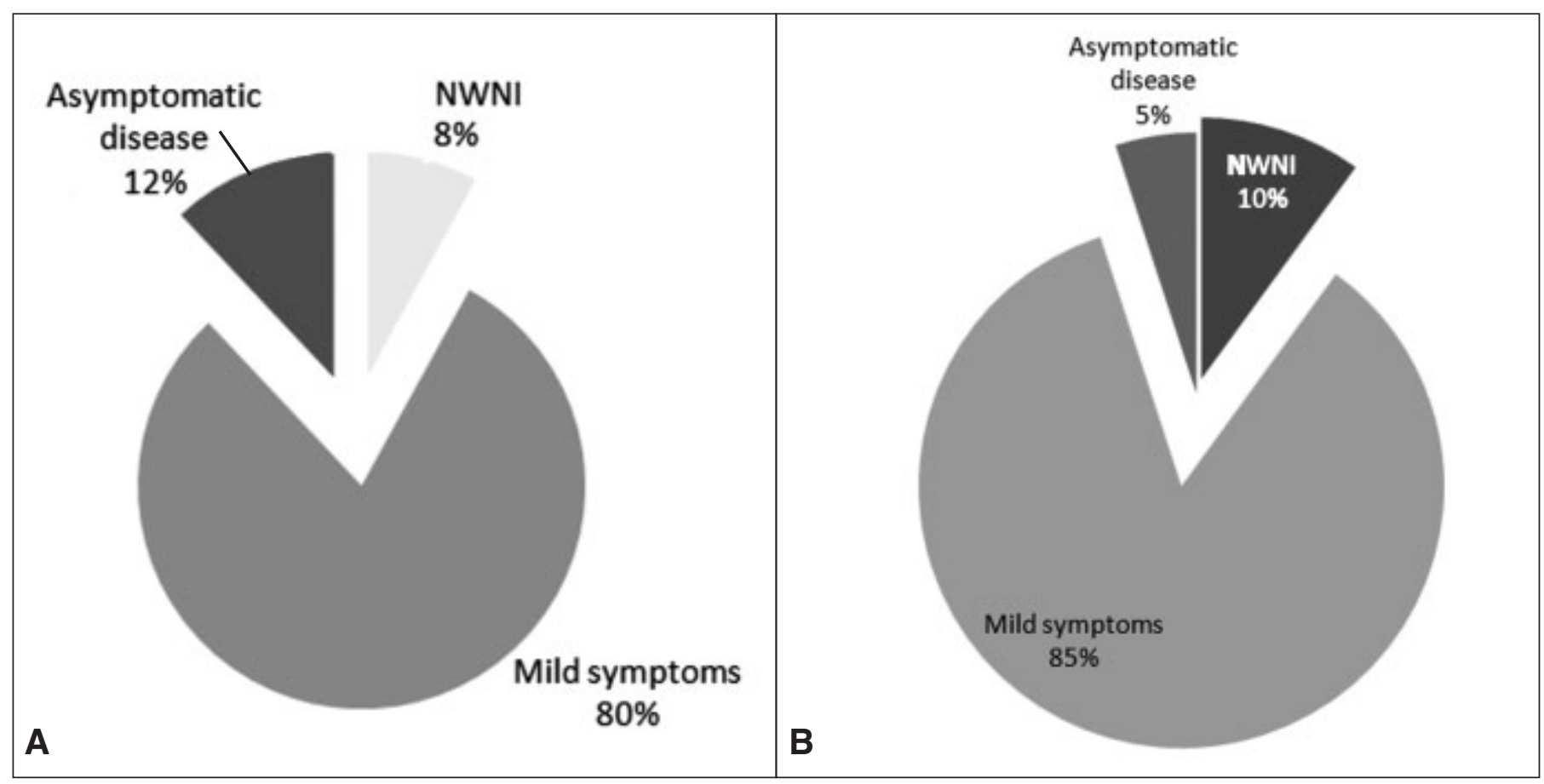

Figure 2: $2 A$ displays the distribution of cases of West Nile infection according the severity of the symptoms in the province of Saskatchewan in 2007. $2 B$ displays similar information than Figure $2 A$ but in the Saskatoon Health Region. This information was reported by the West Nile Virus national surveillance.

Timing (Figure 3): One (2\%) case appeared in June, one $(1.8 \%)$ in July, $47(82 \%)$ in August, five (9\%) in September, two $(4 \%)$ in October and one $(2 \%)$ in November. General symptoms: $44(77 \%)$ patients had fever, 19 had neck stiffness (33\%), 18 had weakness (32\%), 18 had shivers or rigors $(32 \%), 10$ had myalgias (18\%), 16 had rash (28\%), 29 had malaise (51\%), 7 had weight loss (12\%), 29 had vomiting (51\%), and 31 had nausea $(54 \%)$.

Neurologic manifestations and syndromes (Figure 4): Headache 25 (44\%), confusion $25(44 \%)$, meningitis $23(40 \%)$, encephalitis 17 (30\%), encephalopathy 14 (25\%), meningoencephalitis $11(19 \%)$, tremor $10(18 \%), 10(18 \%)$ acute flaccid

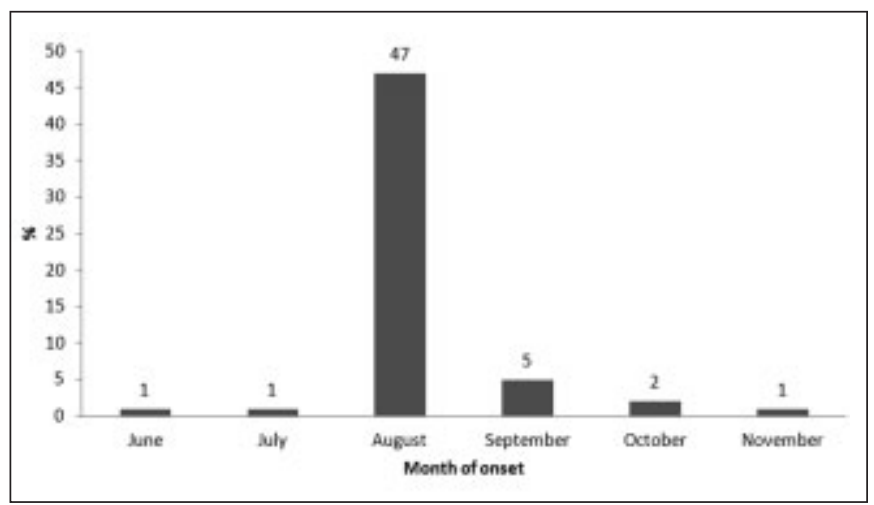

Figure 3: This figure shows the distribution of cases according the month of symptoms onset of cases in the Saskatoon Health Region $(n=57)$. paralysis, myoclonus $1(2 \%)$, nystagmus $2(4 \%)$, diplopia 2 (4\%), dizziness 2 (4\%). (Figure 4)

Characteristic of cerebrospinal fluid (CSF) (Mean (Range): Protein $0.83 \mathrm{~g} / \mathrm{dL}$ (0.38-1.44), Glucose 3.8 (2.4-13.8), cells 155 (1-585), \% lymphocytes 53.2 (4-91), \% neutrophils 37.6 (1-16) Blood work: Red blood cells 4.3 (5.3-2.1), white blood cells 10.8 (2.6-79), hemoglobin 136.9 (86-173), platelets 197 (15-419), ALT 32.5 (10-99), AST 37.2 (13-140), serum glucose 7.0 (4.122.9), creatinine 85.3 (33-148), urea 5.9 (2.2-18.7), Na 134 (126144), K 3.8 (3-5.4), Cl 101 (90-111).

Treatment and outcome: Patients had a stay in hospital of seven days in average (1-37), generally with good outcome.

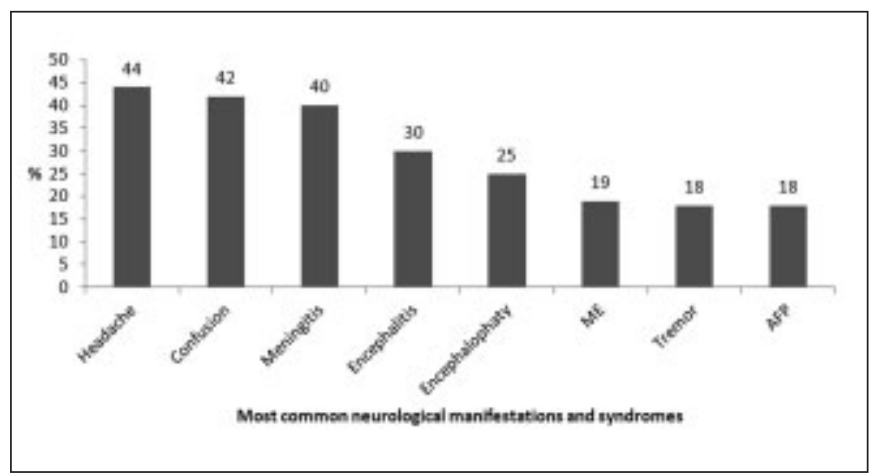

Figure 4: The figure displays the most common neurological manifestations and syndromes of NWNI in the 57 cases reported in the Saskatoon Health Region. ME=meningoencephalitis 
Three patients $(5.7 \%)$ died because of comorbid conditions during the admission.

\section{DISCUSSION}

West Nile virus was first isolated in 1937 from the blood of a woman with fever in the West Nile district of Uganda. The next evidence of activity occurred in the 1950s when WNV was isolated from mosquitoes and birds and identified as the etiologic agent in sick children in North Africa and the Middle East ${ }^{4}$. Neuroinvasive West Nile disease was first documented during an outbreak in elderly patients in Israel in 1957. In North America, the first infection was recognized was in New York in 1991, although the mode of introduction remains unknown ${ }^{4}$. The largest epidemics of neuroinvasive disease caused by WNV in North America occurred in 2002 and 2003 in the US, with 2946 and 2866 cases, respectively ${ }^{5}$. The first documented cases in Canada were in 1999. Saskatchewan experienced its first ever outbreak of WNVI during the summer of 2003. Since the establishment in 2003 of the surveillance program by the government of Canada, a clear epidemiological view of the WNI in Canada has been depicted. Since 2003, cases have been reported yearly with a higher number in 2002 (414 cases), 2003 (1481) and 2007 (2215).

This report is based on the largest outbreak of cases since 2003, and will serve as an important building block for future epidemiologic studies of NWNV in North America and elsewhere. There are no large descriptive studies of NWND in Canada to date. The outbreak in Saskatchewan was the largest reported since the first death was reported in Canada in 1999. The Government of Saskatchewan surveillance program reported that $10 \%$ of cases of West Nile fever developed NWND. In our study the percentage of cases with NWND approaches $16 \%$. The main reason for this discrepancy probably relates to case definitions and ascertainment strategies. We reviewed the charts from all patients admitted to our center with suspicion of NWND, and with careful application of accepted criteria by neurologists, we were able to identify additional cases.

In the US, the rates of NWND are variable; for example in 1999 it was 59\%, 2000 19\%, 2011 64\%, with an average percentage of 40.3 between 1999 and $2007^{2}$. In Canada the rates of NWNI are also variable (Figure 5) between 9.7 and 52\%. The reported rates in Saskatchewan are lower compared to the national rate. This could be related to regional predisposition in patients across the different Canadian provinces. Interestingly the percentage of NWND is not dependent on sample size, being higher in years where the overall number of WNV cases was stable or lower than previous.

The range of symptoms associated with WNVI extends from uncomplicated febrile illness to meningitis, neuropathies, muscle weakness, paralysis, and encephalitis. Symptoms generally become apparent 2-14 days after infection by mosquito bite. Approximately $80 \%$ of infected individuals are asymptomatic. The majority of symptomatic patients present with flu-like symptoms. NWND syndromes include meningitis, encephalitis, and acute flaccid paralysis. Movement disorders including Parkinsonism, tremor, dyskinesias, and myoclonus can be seen. Opsoclonus has also been reported ${ }^{6,7}$. Sejvar et $\mathrm{al}^{8}$ reported the neurological manifestation in 16 patients with NWND from 39 suspected cases. Five (31\%) patients had meningitis, 8 (50\%)

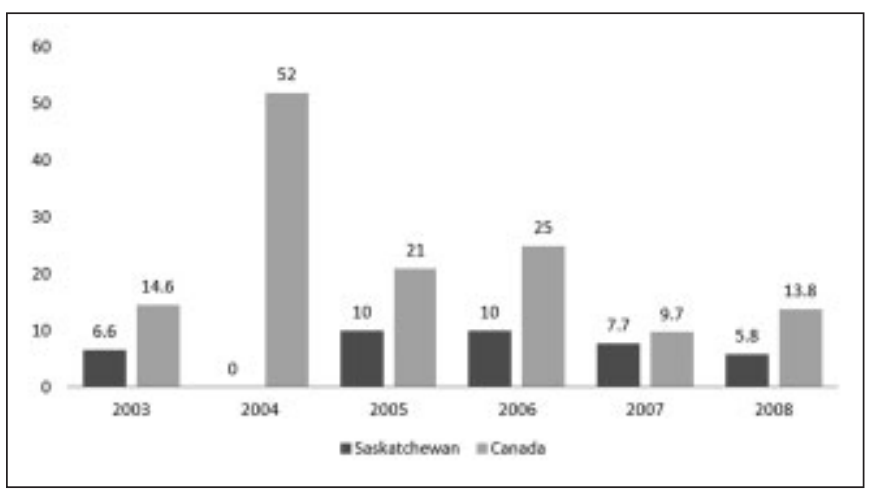

Figure 5: This figure shows the percentage of cases with NWN from the total number of people with WNI in the province of Saskatchewan and Canada.

had encephalitis, 3 (19\%) acute flaccid paralysis, 15 (94\%) patients tremor, myoclonus in $5(31 \%)$ and Parkinsonism in 11 (69\%). One patient died, but overall all the patients had a favourable outcome. Our study showed a high percentage of patients with meningitis, encephalitis or meningoencephalitis as was expected, being one of the most common manifestations of NWNI. Our study showed that $32 \%$ of patients had tremor. Postural and kinetic tremor has been reported as a feature of adult West Nile virus encephalitis in 10 to $50 \%$ of cases, and in the majority of cases the tremor disappears over few months ${ }^{8,9}$. Acute flaccid paralysis has been reported in in 50 to $80 \%$ of patients with West Nile virus encephalitis ${ }^{10}$, which can manifest as a Guillain Barre type syndrome, or resemble polio/anterior horn cell disease ${ }^{10}$. In our cohort the majority of patients had a Guillain-Barre type paralysis that resolved in a few weeks. Only one patient had persistent weakness that was treated with IVIG. Our study is the first in Canada describing the clinical manifestations of NWNI in the largest outbreak reported in Canada and in a single province. The early recognition of neurological signs in cases of WNVI is of significant public health and epidemiologic importance. The rates of WNVI have fluctuated widely and unpredictably over the last decade, and certainly new outbreaks are expected, as evidenced by a small resurgence in $2012^{3}$. While treatment is mainly supportive, improved understanding of mechanisms and risks for NWNI will be beneficial for development of prevention strategies and optimizing treatment, in addition to improving the accuracy of prognostication. Overall our patients had a good prognosis with a low mortality $(5 \%)$ in agreement with other studies ${ }^{8}$.

Proposed risk factors for West Nile disease include age (between 40 and 50 years), diabetes, chronic renal disease, race/ethnicity (being black) and possibly a history of hypertension or cardiovascular disease ${ }^{11,12}$. Outdoor activity without the use of personal protective clothing, particularly during the high-risk periods of dawn and dusk, and exposure in areas that provide a conducive environment for mosquito breeding, have been shown to be important risk factors for contracting $\mathrm{WNV}^{13}$. A serosurvey conducted in New York City after the outbreak of West Nile encephalitis in 1999, found that individuals who spent more than two hours outdoors after dusk or dawn (peak biting periods for the Culex mosquito genus), and 
persons who did not use the insect repellant diethyltoluidine (DEET) had the highest rates of West Nile 15 virus seroprevalence ${ }^{14}$. They also found that having seen a dead bird in one's neighbourhood was associated with a higher rate of infection ${ }^{14}$. A 1996 study in Romania concluded that risk of infection was significantly higher for apartment dwellers with flooded basements ${ }^{15}$. One of the limitations of our study is the lack of a comparison group of patients with asymptomatic disease in order to identify risk factors. Even with the lack of a control group, our patients appeared to have similar comorbidities to those reported in the literature, including diabetes, hypertension and immunosuppression. The timing of NWNI in our study supports outdoor activity as a risk factor.

Neurological manifestations identified in our study provide very useful information for physicians working in NorthAmerica and around the world. The recognition of neurological symptoms and syndromes is very relevant to improve the diagnosis and treatment of patients. The cases of WNVI fluctuate every year and have been low for the last four years, probably related to government campaigns to prevent WNI, which is directly related to the establishment of the surveillance program by the Government of Canada. The rates of NWNI also change every year in Canada and do not depend of the number of cases per year. Neurological manifestations such as tremor and acute paralysis should be recognized by physicians in Canada in order to optimize and improve supportive treatment. This report is based in the largest outbreak in Canada and focused in a single province, serving as foundational information for future descriptions in Canada and internationally.

\section{ACKNOWLEDGEMENTS}

This research was supported by research grants from the University of Saskatchewan and the Royal University Hospital Foundation in Saskatoon, Saskatchewan through the Mudjadik Thyssen Mining Professorship in Neurosciences.

\section{REFERENCES}

1. Kramer LD, Li J, Shi PY. West Nile virus. Lancet Neurol. 2007;6 (2): $171-81$.

2. Murray KO, Walker C, Gould E. The virology, epidemiology, and clinical impact of West Nile virus: a decade of advancements in research since its introduction into the Western Hemisphere. Epidemiol Infect. 2011;139(6):807-17.

3. West Nile Virus MONITOR. Public Health Agency of Canada. 2012. Ref Type: Internet Communication

4. Kramer U, Spector S, Nasser W, et al. Surgical treatment of hypothalamic hamartoma and refractory seizures: a case report and review of the literature. Pediatr Neurosurg. 2001;34(1):40-2.

5. Hayes EB, Gubler DJ. West Nile virus: epidemiology and clinical features of an emerging epidemic in the United States. Annu Rev Med. 2006;57:181-94.

6. Sayao AL, Suchowersky O, Al-Khathaami A, et al. Calgary experience with West Nile virus neurological syndrome during the late summer of 2003. Can J Neurol Sci. 2004;31(2):194-203.

7. Alshekhlee A, Sultan B, Chandar K. Opsoclonus persisting during sleep in West Nile encephalitis. Arch Neurol. 2006;63(9):1324-6.

8. Sejvar JJ, Haddad MB, Tierney BC, et al. Neurologic manifestations and outcome of West Nile virus infection. JAMA. 2003;290(4):511-15

9. DeBiasi RL, Parsons JA, Grabert BE. West Nile virus meningoencephalitis in an immunocompetent adolescent. Pediatr Neurol. 2005;33(3):217-19.

10. Saad M, Youssef S, Kirschke D, et al. Acute flaccid paralysis: the spectrum of a newly recognized complication of West Nile virus infection. J Infect. 2005; 51(2):120-7.

11. Murray KO, Koers E, Baraniuk S, et al. Risk factors for encephalitis from West Nile Virus: a matched case-control study using hospitalized controls. Zoonoses Public Health. 2009;56(6-7): $370-5$

12. Murray K, Baraniuk S, Resnick M, et al. Risk factors for encephalitis and death from West Nile virus infection. Epidemiol Infect. 2006;134(6): 1325-32.

13. Brandt AL, Martyak N, Westhoff J, et al. West Nile virus. Mil Med. 2004;169(4):261-4.

14. Komar N, Panella NA, Burns JE, et al. Serologic evidence for West Nile virus infection in birds in the New York City vicinity during an outbreak in 1999. Emerg Infect Dis. 2001;7(4):621-5.

15. Tsai TF, Popovici F, Cernescu C, et al. West Nile encephalitis epidemic in southeastern Romania. Lancet. 1998;352(9130): 767-71. 